Pragmatics 7:3.397-415

International Pragmatics Association

DOI: $10.1075 /$ prag.7.3.06gut

\title{
ON THE SYSTEMATIC DEPLOYMENT \\ OF OKAY AND MMHMM \\ IN ACADEMIC ADVISING SESSIONS ${ }^{1}$
}

Anna M. Guthrie

\section{Introduction}

This study originally began as an investigation of some of the uses of okay in academic advising sessions. These sessions are an example of what Heritage \& Greatbatch (1989) refer to as "quasi-conversational" institutional talk-in-interaction, that is, talk-in-interaction that is institutional insofar as (a) one of the participants is a representative of an institution and the other is a layperson, (b) the activities in which the participants are engaged are taskand role-based, and (c) the participants' orientation to the institutionality of the interaction is evidenced through the ongoing talk. However, despite the institutionality of the setting, the turn-taking and sequential structures are more like those found in ordinary conversation, as opposed to those found in institutional settings such as a courtroom, a public hearing, or a press conference (He 1993: 8).

My initial exploration of the data confirmed Beach's (1993) distinction that okay is primarily produced in one of two positions relative to the turn in which it occurs: either turn-initially, thus preceding further turn components, or as the whole of a speaker's turn. The instances of okay that I became interested in were those which were 'free-standing,' that is, those which comprise the entirety of a speaker's turn. However, this distinction was not enough since the okays that are produced in this way can be doing different jobs interactionally, that is, they come in response to some specific prior utterance which is doing a particular job. One interactional job that okay can do is affirmatively respond to a question, as in the following example taken from Beach (1993: 330):

\section{(1) Sacks: 4/1/72:16}

A: $\quad$ Can I borrow your car?

2 B: When?

3 A: This afternoon.

B: --> Okay.

\footnotetext{
${ }^{1}$ I would like to thank the following people for their contributions to this work: Agnes Weiyun He for making available the data which she collected for her doctoral dissertation in the Interdepartmental Program in Applied Linguistics at UCLA, 1993; John Heritage for all of his help and guidance on the many earlier versions of this paper; and Marianne Celce-Murcia for her insightful comments and for originally suggesting okay as a phenomenon worth studying.
} 
As Beach points out, this okay at line 4 comes as the response to the initial question by A at line 1 , following the insertion sequence, which is another question/answer adjacency pair initiated by B. In this case, the okay is synonymous with yeah or any other affirmative response to a yes/no question.

Another use of free-standing okay is as a "third turn receipt," that is, it is produced by the initiator of a question or request following an "affirmative, acceptable, and/or clarifying answer" (Beach 1993: 331):

(2) FN\#6: (Davidson 1984:127)

$1 \quad$ A: $\quad$ You wan' me bring you anything?

$2 \quad(0.4)$

3 B: $\quad$ No: no: nothing.

$4 \quad$ A: $-->\bar{A} \mathrm{~W}: k a y$.

In this example, A produces the awkay as an acceptance of B's answer in line 3. However, as Beach notes, this type of okay, as a third turn receipt, can also occur in a number of versions and in a variety of environments: it can serve to receipt clarifying, inviting, offering, the giving of information, and so on. It is this use of okay, to receipt a prior turn, a use which I shall refer to as an acknowledgement token, that is the focus of this paper.

However, as I began to look through the data for instances of this type of okay, I noticed that there were also a great number of free-standing $m m h m m s$ which were used in a very similar way. In fact, the two seemed interchangeable, at least in a great number of cases. For example, in the following instance, the student produces an $\mathrm{mmhmm}$ in response to the information she is given by the advisor, but we can easily imagine an okay being produced in this same slot:

(3) $\quad[\mathrm{CS} 1 ; 2: 49-3: 03]$

1 A: $=$ Right, $\underline{I}$ don't know (.) what I hafta do ta make it okay $\mathrm{n}$ here er do I 2 hafta do [anything]

3 A: $\quad$ [nothing.]

$4 \quad(.6)$

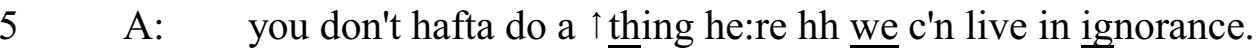

6 S: --> Mmhmm,

$7 \quad(1.0)$

The research question then became: are these two acknowledgement tokens, when they are used in this way, in fact interchangeable, or are there specific uses for each, or places where one may occur or is more likely to occur than the other? I will argue that there is indeed a difference, at least for some speakers - for those speakers who do differentiate between the two, $\mathrm{mmhmm}$ is used as a "continuer" while okay is used as an "acknowledgement token"; as such, okay comes following an utterance which is in some way "more complete" than the utterances which an $m m h m m$ follows. This then leads to the conclusion that despite the assumed randomness of small verbalizations such as $m m h m m$ and okay, or the 
notion that naturally occurring conversation is "messy" and unpredictable, there is, in fact, systematicity in the smallest elements of conversation.

The remainder of the paper is organized in the following way: section 2 gives a discussion of the relevant literature, and section 3 describes the data and methodology used for the study. Section 4 gives examples from the data, with detailed analysis of those examples. Section 5 presents the statistical procedures used in the quantitative analysis, and section 6 gives a "deviant case analysis." Section 7 discusses the implications of this work, with suggestions for further work in this area.

\section{Relevant literature: Turn Constructional Units, acknowledgement tokens}

Beginning with the highly influential work of Sacks, Schegloff, \& Jefferson (1974) and continuing on through recent work by Ford, Fox, \& Thompson (1996), Ford \& Thompson (1996), and Lerner(1996), work done in the Conversational Analytic framework has sought to identify the components which make up a speaker's turn at talk. Noting that, for the most part, one speaker talks at a time, and that smooth transition from one speaker (with little or no overlap as well as little or no gap) is most often the case, Sacks et al. (1974) describe a systematic organization for turn-taking in conversation. In order for this orderly change of speakers to take place, they propose that as listeners, we monitor a speaker's talk as it unfolds, listening for a place which we recognize as one at which speaker change might take place. If we actually wait until such a place arrives, we would have a gap between speakers, but since such a gap is not the usual case, we project and predict when the current speaker's turn may end and another participant may take the floor, based up on the talk that we are hearing.

To be able to predict these places where speaker change might be possible, a speaker's turn must consist of recognizable units--what Sacks et al. refer to as Turn Constructional Units, or TCUs. In English, according to Sacks et al., these units can be sentential, clausal, phrasal, or lexical constructions (1974: 702). When a speaker gets the floor and begins a turn, that speaker is initially entitled to one unit of whichever type the speaker employs - one sentence, one clause, etc. Listeners are able to recognize which type of unit is underway, and therefore can project what it will take for such a unit to come to completion. The first possible completion of such a unit is a place which listeners recognize as a point of possible speaker transition - places which Sacks et al. call Transition Relevance Places, or TRPs.

However, a speaker can also indicate in a number of ways that he or she has not designed a turn to be complete after just one Turn Constructional Unit. A speaker may indicate, with that first TCU, that he/she plans a multi-unit, or extended turn at talk. For example, a speaker may display to the listeners that a story or a joke is upcoming; in cases such as this, the hearers understand that the speaker will need more than one TCU to complete that story or joke. A temporary suspension of the usual "rule" of one-TCU-perturn is collaboratively achieved by the participants - the speaker has implicitly "asked" for an extended turn at talk, and the listeners, by not attempting to gain the floor and begin a turn after the completion of the speaker's first Turn Constructional Unit, have implicitly "agreed" to respect the current speaker's multi-unit turn.

But it is not the case that once a speaker has embarked upon a multi-unit turn that 
the recipients do not produce any interaction at all; it has long been noted that during an extended spate of talk, the recipients, while not starting up full utterances, do interject behavioral tokens, both verbal and non-verbal. Quite common are head nods, smiles, and minimal verbalizations such as uh huh, okay, good, I see, really, and so on (Schegloff 1982: 77). Traditionally, such bits of behavior have been considered collectively (Dittman \& Llewellyn 1967; Fries 1952), with perhaps the most widely used term to describe such behavior, "back-channel communication," introduced by Yngve (1970). In the body of literature which describes this behavior, the consensus is that these particles, or acknowledgement tokens, are used to display attention, understanding, and interest, as well as to "keep the conversation going smoothly" (Dittman \& Llewellyn 1967: 342). Schegloff (1982) notes that perhaps the most common use of $u h$ huh and other tokens is as a "continuer," that is, to demonstrate that the producer of such a token recognizes that an extended turn at talk is underway, and that the current speaker's turn is not yet complete. Generally, these tokens are free-standing, and by producing such a token as opposed to a full turn at talk, a recipient passes on an opportunity to initiate repair, that is, to indicate a lack of understanding regarding the immediately preceding talk. If these tokens then pass on an opportunity to do repair, "the basis seems clear for the ordinary inference that the talk into which they are interpolated is being understood, and for the treatment in the literature that they signal understanding" (Schegloff 1982: 88).

When these acknowledgement tokens are produced during another speaker's extended turn at talk, they do not occur just anywhere within the current speaker's turn, but are most often placed systematically at points which are syntactically relevant - often these places are points at which a TCU might possibly come to completion. It is sometimes the case that the current speaker's turn is in fact designed to be complete at that point, and sometimes it is the case that the current speaker displays an intention to continue the turn.

As Ford, Fox, \& Thompson (1996) and Ford \& Thompson (1996) point out, although Sacks et al. do not necessarily "define" the TCU as syntactically-based, the Sacks et al. article, as well as the related subsequent literature, all tend to focus on syntax as the primary conceptualization of TCUs. But as Ford \& Thompson (1996) show, speakervalidated TRPs, that is, Transition Relevance Places which the participants recognized as such, and at which speaker change actually did take place, are most frequently points at which possible syntactic completion converges with intonational and pragmatic completion. In other words, listeners are not just attending to the current speaker's syntax, but are also using intonation and pragmatic elements of completion to be able to predict when that speaker's turn may be finished.

In another examination of the makeup of Turn Constructional Units, Lerner (1996) defines what he calls a compound TCU - prototypically, this is a construction of the if $X$, then $Y$ type, with "conditional access" to the current speaker's turn granted to the recipient between the two components. In other words, although it is clear to the hearer of such a construction that the current speaker's turn is not yet complete, this construction allows for an enhanced "possibility of a recipient interposing talk before possible completion of a TCU" (p. 239). Lerner points out that one of the primary actions that occurs between components of a compound TCU is anticipatory completion of that unit - that is, the recipient projects what is coming and completes the utterance for the speaker. But as Lerner also notes, this is not the only action which occurs at such junctures - he shows that 
"continuers can also be used in the same way at the completion of the primary component of a compound TCU," as in the following example taken from Lerner (p. 251):

(4) [Mother's Day]

$1 \quad$ D: $\quad$ s- so if if ah you were strong in yer feeli:ngs about (0.2) people

$2 \quad(0.2)$

3 A: $-->\mathrm{Mm} \mathrm{hm=}$

4 D: $\quad=$ your thet you li:ked (0.3) an it was completely (.) contras=to (0.4) what your mother (.) thought was right...

The use of an acknowledgement token at such a place demonstrates the producer's acknowledgement of the current speaker's turn-so-far as incomplete, and the expectation that the current speaker should continue.

As noted, traditionally the acknowledgement tokens were considered in the aggregate; as Jefferson (1984a) points out, they are generally thought of "as a class," and we tend "to produce various considerations about the class as a whole" (1984a: 199). However, recent work has begun to turn away from consideration of these forms collectively. Despite the apparent randomness of a producer's choice among the various tokens, some more specific uses and functions of some of the previously mentioned tokens or particles (uh huh, yeah, $\mathrm{mm} \mathrm{hmm,} \mathrm{oh,} \mathrm{okay)} \mathrm{have} \mathrm{been} \mathrm{observed} \mathrm{(Schegloff} \mathrm{\&} \mathrm{Sacks:}$ 1973; Jefferson 1984a; Heritage 1984; Merritt 1984; Heritage \& Sefi 1992; Beach 1993).

In an investigation of yeah and $\mathrm{mm} \mathrm{hmm}$, Jefferson (1984a) finds that while not everyone makes a distinction between the two tokens, for those who do, $\mathrm{mm} \mathrm{hmm}$ is used to mark "passive recipiency," while yeah is used to mark an incipient move into speakership, although that move to speakership may occur some distance following the token. That is, by producing an $\mathrm{mm} \mathrm{hmm}$, the recipient of the extended turn is displaying her or his understanding that the other participant has the floor, and that that current speaker's turn is not yet complete. But by producing a yeah, the recipient displays an understanding that he/she considers the others speaker's turn either to be complete or to be coming to completion, and that the yeah producer is ready to take the floor for a turn, to shift from the role of recipient-so-far to the role of speaker. While Jefferson does not attempt to generalize her findings to all speakers, she illustrates that of those whose usage she investigated, for those who use both tokens, "the recipiency/speakership distinction seems to hold" (p. 205).

\section{Data \& methodology}

The data consist of a series of tape-recorded academic advising sessions which took place at a large west coast state university during the 1990-91 academic year. These sessions were then transcribed according to the transcript notations developed by Gail Jefferson, which are those generally used for Conversation Analytic research (1984b: ix-xvi). The names of the participants were changed to protect their anonymity. All of the participants in the sessions used for this study are native speakers of American English, and all of the participants granted permission to have their sessions taped and were aware that the tapes 
would be used for linguistic analysis. ${ }^{2}$ The students, both male and female, range from entering freshmen to seniors who are about to graduate, and include students in good academic standing and students with serious academic problems. These students present a number of specific concerns to the advisors, who are either professional advisors or are trained graduate student advisors. The sessions are arranged in one-half hour appointments, and while some students have been referred to an advisor, i.e., an appointment is mandatory for the student's particular problem, most of the appointments are student-initiated. A total of seven sessions are used for the current study.

The sessions are all dyads, with one student and one advisor discussing the student's problems or concerns. While some sessions use the full half-hour time slot allotted and others are somewhat briefer, all of the sessions follow a general pattern of progression through the following stages:
(1) greetings
(2) presentation of the problem
(3) informing/advising: working through the problem
(4) confirmation
(5) closings

While acknowledgement tokens occur throughout the advising sessions, those under investigation here, which constitute the majority of the tokens, occur almost exclusively in phase 3 - informing/advising: working through the problem. Because advice giving/getting is the primary reason for the session, the orientation of the participants to the task at hand, as well as the institutionality of the interaction, is perhaps most evident during this phase. What both participants are oriented to is the idea of the advisor as advice/information holder and dispenser, and student as advice/information seeker and recipient. The different roles the participants play in the interaction are evidenced in a number of ways, acknowledgement tokens being only one.

Of the 282 free-standing tokens found in the data, the majority, $77 \%$ (218), were produced by the students. This is one of the ways in which the different roles of the participants are evidenced - specifically, with the advisor as the information giver, the advisor produces many more extended turns at talk with numerous slots along the way which are prime locations for an acknowledgement token to be produced by the recipient.

Consequently, only those okays and mmhmms produced by the students in these seven sessions are considered for this paper. The students' free-standing tokens were marked on the transcripts, with the prior turn, i.e., what the acknowledgement token was produced in response to, then coded as being (1) a Lerner-type compound TCU, (2) a place of possible syntactic completion only, or (3) a place where possible syntactic completion plus intonational completion converged. ${ }^{3}$ Because position 1, the Lerner-type compound,

\footnotetext{
${ }^{2}$ Some of the original sessions which were recorded and transcribed did include non-native speakers of English; however, those sessions which included non-native speakers were not used for this particular study.

${ }^{3}$ There were a small number of acknowledgement tokens produced following places which could not be clearly classified as one of these three positions - these tokens were not counted in this study and will require further analysis.
} 
is clearly a slot which is "in the middle of" the other speaker's, the advisor's, turn, we might predict that if one of the two tokens functions primarily as a continuer, this would be a prime location for it to be produced. Similarly, if one of these tokens is used primarily as acknowledgement, that is, to display an understanding that the other's turn is complete or finished, we might predict that position 3, a place where syntactic and intonational completion converge, would be a likely location for this token.

While the methodology employed in the analysis of the tokens okay and $\mathrm{mmhmm}$ in these academic advising sessions is twofold - both qualitative and quantitative, the initial research design was solely qualitative, using the methodology of Conversation Analysis. While this approach to social interaction was first applied to the study of ordinary conversation, in recent years its application has spread to include a number of institutional settings, such as news interviews (Clayman 1993; Greatbatch 1986; Heritage 1985), emergency calls (Whalen \& Zimmerman 1987; Zimmerman 1984), medical interaction (Gill 1994; Halkowski 1994), and courtrooms (Atkinson 1992). It is through the initial qualitative analysis of the data that the means for a quantitative analysis, i.e., the identification of the variables and the specific statistical test to be used, was determined.

\section{Examples from the data}

\section{Position 1: Compound TCU}

Although Lerner describes these compound TCUs as being prototypically of the if $x$, then $y$ construction, in these data compound Turn Constructional Units are constructed with a number of other subordinating conjunctions, such as since, for, after, or because - these constructions all allow conditional access to the speaker's turn between the two clauses. Example (4) shows a student producing an $\mathrm{mmhmm}$ at such a place:

\section{(5) $\quad[\mathrm{CS} 2 ; 8: 25-34]$}

1 A: $\quad[\cdot h h$ you've got four classes that you can repeat.

2

$$
\text { (.2) }
$$

A: $\quad$ you can repeat one cla:ss (.) one time, (.4) for a total of four classes. hhh a:nd for those first four classes, [the sec] ond set of grade points

S: --> [Mmhmm, ]

A: replaces the first one [in yo ]ur grade point

S: $\quad$ [Mmhmm, ]

A: average. hh the grade will always show but the grade points get replaced.

$$
\text { (.2) }
$$

In example (5), the student produces an $\mathrm{mmhmm}$ at line 6, after the clause and for 
those first four classes; this comes at a point where the advisor is clearly not yet finished with her turn syntactically, but because of the construction of the utterance, conditional access is provided for the recipient to produce a continuer. Not only is the advisor's turn obviously not yet complete in a syntactic sense, the intonation used displays that there is more to follow, and the student's use of $\mathrm{mmhmm}$ serves as a continuer here.

Example (6) shows a student's production of okay in a Lerner-type compound:

(6) $[\mathrm{CS} 2 ; 4: 19-25]$

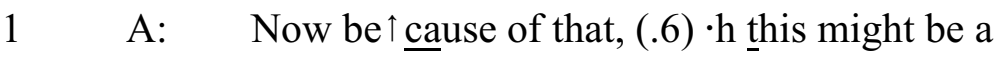

2 problem.

$3 \quad(.7)$

4 A: alright? [you're gonna hafta repeat] three $\underline{\mathrm{E}},(.2)$

5 S: $\quad[(\quad)$ one oh one $\underline{A}$ ? $]$

6 A: and this:: since this is now a prep, [you're g]=

7 S: $->\quad$ [Oka:y, ]

8 A: $=$ onna hafeta repeat that too. $=$

Similar to example (5), in this example, the student produces an okay following the first clause, since this is now a prep, and is given conditional access to the turn because of the subordinated construction used by the advisor in this utterance. However, in this example, despite the lack of falling intonation, there is a stronger sense of pragmatic completion than in example (5); the advisor has said that the student will have to repeat three E and this, so when she adds since this is now a prep, you're gonna hafeta repeat that too, she recompletes the information already given.

\section{Position 2: Syntactic Completion}

The second position under consideration in which these two free-standing tokens appear is that of possible syntactic completion - i.e., a speaker produces a token at a point in the other speaker's turn which, if the turn ended there, would be considered grammatically complete. In some cases, this is a point at which the turn does in fact end, but in other cases, the producer's token comes in overlap with the first speaker's turn, because the first speaker has not designed the turn to be complete at that point. Example (7) illustrates $m m h m m$ as it occurs following a point of possible syntactic completion. The student, while using the token as a continuer (Schegloff 1982), does not interject it just anywhere in the advisor's turn, but at a point at which the advisor's turn might be considered complete, syntactically.

(7) $[\mathrm{CS} 2 ; 10: 10-22]$

2 A: $\quad$ so:: ${ }^{\circ}$ yeah $^{\circ}>$ doesn't matter. $<$ tch $\cdot$ hhh the other

3 thing you're gonna wanna do for the department i:s

4 ta get yer overall grade point average back up 
$5 \quad$ [b'cause $]$ they

$6 \quad \mathrm{~S}: \rightarrow \quad \mathrm{Mmhmm}$,

$7 \quad$ A: $\quad$ have an overall (.4) that they they expect. $=$

$8=[$ for the $]$ se as well.so $\cdot h$ this will help=

9 S: $\quad$ [Yeah ]

10 A: =considerably an' obviously the [higher] you go,

11 [( )]

12 S: Yeah

13 A: the bigger $u: m$ the: the reduction in the

14 deficit.so $\cdot$ hh that's gonna be very helpful.

15 (3.)

In this example, while S's mmhmm comes at a point when the advisor's turn might be complete syntactically (...get your overall grade point average back up), A's intonation clearly indicates that she has not designed this turn to be complete at this point. The student's $\mathrm{mmhmm}$, which serves as a continuer here, comes in overlap as A continues her turn.

Example (8) shows the token okay in a similar environment:

(8) $[\mathrm{CS} 2 ; 7: 39-45]$

1

2 A: $\quad[\cdot h$ h s]o what we're talking abou:t $\underline{\mathrm{i}}:: \mathrm{s}(1.2)$

3 tch=removing? (1.6) a minus?=ten point eight,

$4 \quad$ S: $-->{ }^{\circ}$ Okay, ${ }^{\circ}=$

$5 \quad$ A: $\quad=$ deficit; (1.) $\cdot$ hh by::: spring ninety two, (.4)

6 by the end, (.3) alright?=hn of spring ninety two.

$7 \quad \cdot h$ a:::nd (1.3) do not increase deficit.

$8 \quad(3$.

In this example, again, the student produces the acknowledgement token at a point in the advisor's turn where that turn could be complete from a syntactic perspective. And again, the advisor displays that she has not designed the turn to be complete at this point by the continuing intonation used for the phrase a minus ten point eight.

\section{Position 3: Syntactic plus Intonational Completion}

The last location to consider is that in which syntactic and intonational completion converge. These are points of possible syntactic completion which also contain falling or final intonation, thus giving the recipient a strong indication that the turn has been designed to be complete at this point. This final intonation can often be projected by a pitch peak typically, when the pitch peak occurs, the turn has been designed to be complete following the next possible syntactic unit. Example (9) illustrates the use of the token $\mathrm{mmhmm}$ at two such points: 
(9) $[\mathrm{CS} 2 ; 6: 37-46]$

$1 \quad$ A: $\quad{ }^{\circ}$ 'kay. ${ }^{\circ} \cdot$ hhhhh what we do::: on the transcript (.)

$2 \quad$ i:s hhh (.4) we have two ways of measuring. (.2)

3 a-g-GPA.hh one of them is a grade point

$4 \quad$ a:verage.an' in order ta get tha:t, you take

$5 \quad$ grade points an' divide by units attemp [ted.

6 S: --> [Mmhmm,=

$7 \quad$ A: $=$ hh when you get into anything more complicated

8 than one quar:ter or a couple of classes, (.2) you

9 hafeta (.) refigure everything.

10 S: --> Mmhmm,=

In this example, the student's mmhmms both come following places of possible syntactic completion, at which the advisor also uses falling, or final intonation. The first $m m h m m$, at line 6 , shows that the student is monitoring the advisor's talk, and hears the pitch peak which precedes falling intonation here; combined with projected syntactic completion, these two elements alert the student that a place where turn transition, from the current speaker, the advisor, to herself may be relevant. But, since the advisor has indicated that there are two ways to figure a GPA, and since she has only described one of them, she continues explaining the system to the student, with the promised second method yet to come. Thus, while the student's mmhmm comes following a place at which both syntactic and intonational completion converge, the advisor's utterance is not informationally or pragmatically complete. The student's second $\mathrm{mmhmm}$ comes, again, at a point where syntactic and intonational completion converge, at line 10.

If we look at example (5) again, we can see that the second $m m h m m$ produced by the student, at line 8 , comes following a point of possible syntactic completion:

(10) $[\mathrm{CS} 2 ; 8: 25-34]$

$1 \quad$ A: $\quad[\cdot h h$ you've got four classes that you can repeat.

$2 \quad(.2)$

3 A: $\quad$ you can repeat one cla:ss (.) one time, (.4) for a

$4 \quad$ total of four classes. hhh a:nd for those first

5 four classes, [the sec] ond set of grade points

6 S: $\quad[\mathrm{Mmhmm}$,

7 A: replaces the first one [in yo ]ur grade point

8 S: --> [Mmhmm, ]

9 A: average. hh the grade will always show but the

10 grade points get replaced.

$11 \quad(.2)$

In this example, what the advisor says to the student could possibly come to completion after the second set of grade point replaces the first one; in fact, when the advisor then adds in your grade point average, it almost seems redundant.

In example (11), the student produces an okay at a similar point: 
(11) $[\mathrm{CS} 3 ; 3: 31-52]$

1 S: $\quad$ so:: (.7) have any of the classes I've ta:ken so

2 far been wa::sted, have I ta:ken any::

3 A: $\cdot$ hhh well, let's take a look.

$4 \quad \mathrm{~S}: \quad \mathrm{Na} \quad[\mathrm{h}$ ha

5 A: $\quad$ [hah

$6 \quad$ A: $\quad$ hh (.4) I doubt if they've been wa-I doubt if

7 they've been wasted.

$8 \quad(1.8)$

9 S: Cuz I have- (.4) I've overloaded on the

10 humanities, (.4) W'I know that much.

11 A: $\cdot$ hh well simply by going in-in a (.) Spanish

12 direction you've taken (.4) numbers of good

13 courses, (.2) in (.) uh humanities, but in terms

14 of overloaded, um: (.5) that may be $\cdot \mathrm{hhh}$ uh (.2)

15 looking at this so far, it doesn't look as if um

16 h you've wwasted any courses that-the courses

17 that you've been taking $\cdot h$ h have been solid, $\cdot \mathrm{hh}$

18 and they are counted toward requirements.

19 (1.)

20 S: --> ${ }^{\circ}$ Oka:y, ${ }^{\circ}$

$21 \quad$ (1.)

22 S: U:m:: (.8) how do I go about: (.8)

23 A: Declaring a major?

24 S: Declaring a major.

Example (11) shows a prototypical deployment of the token okay. S produces this okay at line 20 after A's turn has been completed; indeed, a 1 second pause follows A's turn before $\mathrm{S}$ responds. Here, the student's okay follows an utterance which is, like the $m m h m m$ in example (9), both syntactically complete and intonationally complete, insofar as it has a pitch peak and final falling intonation. However, in this example, the advisor's utterance is also informationally, or pragmatically, complete, as evidenced by the student moving on to the next matter at line 22 .

So while the students do produce the two tokens in all three positions, the okays seem to have a tendency to appear more often following an utterance which has a greater sense of pragmatic completion than those places where an $\mathrm{mmhmm}$ is produced. Indeed, as the quantitative analysis will show, despite the apparent interchangeability of the two tokens in the three positions, the participants demonstrate an orientation to the use of $m m h m m$ as a continuer and okay as an acknowledgement token. That is, the mmhmms come in the "less-complete" slots, and the okays come in the "more-complete" slots.

\section{Quantitative analysis}

In quantitative terms, the variables identified through the qualitative investigation 
are: the dependent variable of token with the two levels okay and $\mathrm{mmhmm},{ }^{4}$ the independent variable of position, with the three levels of Lerner-type compound TCU, syntactic completion, and syntactic plus intonational completion, and the secondary independent variable of speaker with the two levels student and advisor. As in the qualitative analysis, only those free-standing tokens produced by the students will be considered in the quantitative analysis. The students' relative frequencies of the two tokens as they occur in the three positions are given in Table 1. Position 1 is the Lerner's compound TCU, position 2 is syntactic completion, and position 3 is syntactic plus intonational completion.

Table 1: Students' Relative Frequencies of Token by Position

\begin{tabular}{lcccc}
\hline \hline Token & Position 1 & Position 2 & Position 3 & Total \\
\hline mmhmm & 20 & 33 & 27 & 80 \\
okay & 6 & 35 & 97 & 138 \\
\hline Total & 26 & 68 & 124 & 218 \\
\hline \hline
\end{tabular}

As Table 1 shows, the relative distribution of the two tokens in the three positions exhibits a symmetrical pattern. Considering the instances of these three positions in which a free-standing token was produced, $77 \%$ of the tokens produced in position 1 are $\mathrm{mmhmm}$, while $78 \%$ of the tokens produced in position 3 are okay. In other words, in position 1, we are likely to get an $m m h m m$ rather than an okay 4 times out of 5, and in position 3, we are likely to get an okay rather than an mmhmm 4 times out of 5 . In position 2, there is an almost even split between the two tokens. While the relative frequencies do show a distributional difference in the tokens which are produced in the three positions, a further statistical test was run to determine if this pattern is indeed statistically significant.

Looking strictly at the relative frequencies of the two tokens as they are produced by the students in the three positions may be misleading statistically. As Table 2 shows, there are vast differences in the total frequencies between the various speakers. For instance, some of the speakers use a great number of both tokens while others use very few, and some speakers tend to favor one token over the other in all three positions.

Table 2: Students' Frequencies of Token by Position

\begin{tabular}{llccccc}
\hline TOKEN & SPEAKER & Pos. 1 & Pos. 2 & Pos. 3 & Total & $\begin{array}{c}\text { Token } \\
\text { Total }\end{array}$ \\
\hline Mmhmm & 1 & 3 & 1 & 2 & 6 & \\
Okay & 1 & 0 & 5 & 6 & 12 \\
\hline Mmhmm & 2 & 13 & 16 & 12 & 41 & \\
Okay & 1 & 9 & 37 & 47 & 88
\end{tabular}

\footnotetext{
${ }^{4}$ While there were some instances of other tokens produced, such as yeah or right, these were very infrequent in comparison to the okays and the mmhmms - a total of 34 other tokens occur in the data, combining those produced by both the students and advisors. Consequently, as in the qualitative analysis, only okay and $\mathrm{mm} \mathrm{hmm}$ are considered in the qualitative analysis.
} 


\begin{tabular}{|c|c|c|c|c|c|c|}
\hline Mmhmm & 3 & 0 & 1 & 0 & 1 & \\
\hline Okay & & 0 & 1 & 4 & 5 & 6 \\
\hline Mmhmm & 4 & 0 & 11 & 7 & 18 & \\
\hline Okay & & 0 & 19 & 19 & 38 & 56 \\
\hline Mmhmm & 5 & 0 & 3 & 3 & 6 & \\
\hline Okay & & 0 & 0 & 1 & 1 & 7 \\
\hline Mmhmm & 6 & 4 & 0 & 0 & 4 & \\
\hline Okay & & 0 & 2 & 4 & 6 & 10 \\
\hline Mmhmm & 7 & 0 & 1 & 3 & 4 & \\
\hline Okay & & 4 & 4 & 27 & 35 & 39 \\
\hline Total & & 26 & 88 & 124 & 218 & 218 \\
\hline
\end{tabular}

As Table 2 shows, there is quite a bit of variation in the frequencies of tokens used by the different students - student 2 uses a total of 88 free-standing tokens, compared with student 3 , who uses only 6 . However, despite the great variance between the total number of tokens used by these two extreme cases, for both students, the largest proportion of their tokens is okay in position 3. This is true for the majority of the students, as well.

Given the extremes in the individual uses of these free-standing tokens, using the mean as the best measure of central tendency is rather questionable, and using a statistical procedure based on means thus becomes suspect. There is a possibility that a speaker who produces many tokens may skew the data; consequently, another approach to a quantitative analysis of the data was needed - one which could control or correct for the extremes in the individuals' uses of the two tokens. The STATA statistical package has a logistic regression procedure (which predicts performance on the dependent variable via one or more independent variables) with the Huber Standard Error, which does control for the extremes in individual performance. Table 3 shows the likelihood of a student producing an $\mathrm{mmhmm}$ rather than an okay in positions 1 and $2 .{ }^{5}$

Table 3: Students' Likelihood of Mmhmm

\begin{tabular}{llccl}
\hline \hline Token & Coefficient & $\mathrm{z}$ & $\mathrm{P}>\mathrm{z}$ & Exponential \\
\hline Position 1 & -2.482847 & -3.505 & 0.000 & 11.97531 \\
Position 2 & -1.220034 & -3.665 & 0.000 & 3.387303 \\
\hline \hline
\end{tabular}

Table 3 illustrates the likelihood that an $m m h m m$ will be produced, rather than an okay in positions 1 and 2, relative to position 3. So for position 1, the Lerner compound,

\footnotetext{
${ }^{5}$ Because there were only six instances of okay produced in position 1, and four of those were produced by one speaker, the statistical likelihood of a student producing okay rather than $\mathrm{mmhmm}$ in position 1 relative to position 2 was not run.
} 
the likelihood of a student producing an $\mathrm{mmhmm}$ rather than an okay is 11.98 times greater, relative to position 3. And for position 2, that of syntactic completion, the likelihood is 3.39 times greater that an $m m h m m$ will be produced rather than an okay. So this means that for the Lerner's TCU slot, the least "complete" slot under consideration, the odds are greatly in favor of a student producing an $\mathrm{mmhmm}$ rather then an okay - that is, using the $\mathrm{mmhmm}$ as a continuer in a slot which, by definition, is a point of non-completion.

Table 4 shows the students' likelihood of producing an okay rather than an $\mathrm{mmhmm}$ in position 3 , relative to position 2 .

Table 4: Students' Likelihood of Okay

\begin{tabular}{llccc}
\hline \hline Token & Coefficient & $\mathrm{z}$ & $\mathrm{P}>\mathrm{z}$ & Exponential \\
\hline Position 3 & -1.262813 & -1.742 & 0.0409 & 3.535352 \\
\hline \hline
\end{tabular}

Table 3 shows the exponential value, which tells us that the odds of a student producing an okay in position 3 rather than an $m m h m m$ are 3.54 times greater. Here the probability of .04 means that only 4 times out of 100 this effect is due to chance, or that we are incorrect in rejecting the null hypothesis.

This is obviously not the case all the time. Those speakers who do not make the distinction between the two tokens in the three positions seem to mask the strength of the relationship between token and position for those who do make the distinction - that is, for those who do make the distinction, the relationship between token and position is quite strong. Like the speakers in Jefferson's study of yeah and $\mathrm{mm} \mathrm{hm}$, for those who do differentiate between the two tokens, the different uses and environments for the tokens is pronounced.

\section{Deviant case analysis}

The methodology of Conversation Analysis often includes what is known as a "deviant case analysis" - an analysis of instances which do not fit the pattern that is being described as normative in some way, but which, by their very non-conformance to the pattern, further support that the practice in question is in fact oriented to by the participants (Atkinson \& Heritage 1984: 2). The following are two examples of "deviant cases":

(12) $[\mathrm{CS} 4 ; 5: 32-43]$

1 A: I'm not sure I've answered your question or:

2 not.hhh

3 S: $\quad$ Alright, it doesn't-s-cuz I've never (.2) thought

4 (.) statistics jus doesn't sound like it'd be all

5 that ba:d if it's just numbers.=

6 A: $=$ It probab-it probably isn't.

$7 \quad(.3)$

8 A: really isn't. hh most people live through it

9 pretty well an' some people-some people enjoy it.= 
$10 \quad$ S:--> $=$ Mmhmm

$11 \quad(2.2)$

12 A: Du-did you have any other (.) thoughts er any

13 other (.4) que:stions:, [ (concer)]

In example (12), the advisor indicates that he has answered the student's question, although he realizes that answer may not have been entirely adequate. He then answers again in line 5, and, by the falling intonation and the pause that follows, displays that he considers the question to have been adequately answered. But when there is no uptake from the student, the advisor upgrades his response from probably isn't at line 6 to really isn't at line 8 . He then adds another Turn Constructional Unit which recompletes his response in lines 7 and 9, again, with final, falling intonation, but the student responds with an $m m h m m$, rather than an okay at line 10. A 2.2 second pause follows, after which the advisor moves on to the next matter, that of closing the session.

Example (13) is another deviant case;

(13) $[\mathrm{CS} 8: 12: 05-12: 26]$

$1 \quad$ A: $\quad$ So if you take (.4) u:h the second session, now

2 (.7) you-you're gonna be stuck in a situation

3 where you may not feel you may be:=

$4 \quad$ [(able to) do it.] [.hh bu:t u:h]=

5 S: [ $\quad$ h yeah becau:se] [uh huh uh huh]

6 A: $=$ but I don't know.ya know th-s-my experience has

7 been the summer courses there: (.6) are not as

8 demanding as they are (.4) during the regular

9 school year because you have less time. $\quad[\cdot \mathrm{hhh}]=$

10 S: [Mmhmm, ]

11 A: =but yeah.as long as you==satisfy:: (.5) level

12 three, $=$

13 S: =yea: [:h my last GE]

14 A: $\quad[\mathrm{u}::: \mathrm{m}]$ th:at would be: uh (.) that

15 would be acceptable, you would $>$ satisfy the

16 requirement but you won't get any units for it.<

17 S: $\quad$ Mmhmm.

$18 \quad(.3)$

19 S: okay.

$20 \quad(.3)$

$21 \quad$ S: okay.

$22 \quad(1.6)$

23 S: $\uparrow$ o $\quad$ kay

24 A: [So an' you're thinking of: o:f u:[:h DeBois?]

In this example, the advisor is describing the consequences of the student's taking some units at a community college during the summer. He has told the student that doing so will satisfy some of her general education requirements, but that she will not get the unit 
credit for the class, which is information that he has already given this student (on the previous page in the transcript). So when the advisor says this, this comes as completion of his explanation of the advantages and disadvantages of attending summer school at a community college. But the student produces an $\mathrm{mmhmm}$ in line 17, which displays that she does not hear the advisor's turn as complete. The advisor does not self select at line 18; rather, a pause ensues, after which the student, now recognizing that the advisor has indeed said all that he plans to on this matter, upgrades her mmhmm to an okay. Another pause follows, which gives further evidence that the advisor has nothing more to add on this particular topic. The cycle of pause/okay occurs three times, with all three tokens displaying closure. That is, the student recognizes that the topical sequence concerning summer school is now over, and in particular, the third okay, with its exaggerated intonation, signals a shift to next matters. The advisor comes in in overlap with this third okay to begin a new question/answer sequence.

Both of these examples demonstrate the participants' orientation to the use of $m m h m m$ as a continuer and okay as an acknowledgement token to be used following utterances which are complete in some sense. In both cases the advisor indicates, syntactically, intonationally, and pragmatically that he or she has come to completion, but the students display that they have not heard the advisors' utterances as complete, and respond with an mmhmm rather than an okay. In both cases, the advisors do not say anything further following this okay, which displays that they had in fact designed their turns to be complete. In the first example, after a pause, the advisor moves on to the next item, and in the second case, after the student has upgraded her response to an okay (and repeated it), the advisor moves on. These examples of deviant cases further support that, at least for these speakers, the practice of $\mathrm{mmhmm}$ as a continuer and okay as a token marking completeness is a practice to which they are oriented.

In the investigation of the students' free-standing tokens in these data, we have seen that (a) the students produce the majority of the free-standing tokens, (b) this difference in frequency is a function of the different roles in the interaction which the two participants play and the sorts of jobs that each role entails, (c) the free-standing tokens can and do appear in all three positions, (d) however, that use is not random, but displays some systematicity, with the use of okay increasing as the "completeness" of the slot increases, and with $\mathrm{mmhmm}$ being used as a continuer, or as Jefferson (1984a) noted, to mark "passive recipiency."

\section{Conclusion}

As an example of quasi-conversational institutional interaction, these advising sessions exhibit elements of both ordinary and institutional interaction. They are institutional insofar as the interaction is very much task-oriented; this orientation to the task at hand is evidenced in the ways in which the role that each participant plays helps to shape the participants' utterances - both positionally and compositionally. This is seen in the numbers and kinds of turns produced by each: many extended turns at talk are produced by the advisors, and many mmhmms and okays are produced by the students while the advisors do their job of advising. Simultaneously, insofar as there are (many) acknowledgement tokens produced in the slots which are provided as an element of ordinary conversation, the 
conversational nature of these encounters is demonstrated.

Together, both the qualitative and quantitative analyses demonstrate that the participants in these advising sessions are oriented to a systematic deployment of the acknowledgement tokens okay and $\mathrm{mmhmm}$. In the qualitative analysis, an examination of both prototypical and deviant examples reinforces the normative nature of this practice. In the quantitative analysis, both the relative frequencies and the logistic regression show that the position has a significant effect on which token will be produced. Specifically, they support the use of $m m h m m$ as a continuer and okay as an acknowledgement token.

While this pattern is one which the participants in this setting display their orientation to as normative, it is still unknown if there are other institutional or noninstitutional settings in which this same pattern may be found. It seems likely that this pattern may be found in settings which have some similarities, such as writing conferences or even doctor/patient encounters. In both of these other settings, the layperson comes to the "expert" with a problem or concern, and, as in the academic advising sessions, the institutional representative is giving some sort of advice or instructions to the layperson. Further comparative studies in other settings may help to determine the generalizability of this pattern.

This investigation into the uses of the acknowledgement tokens mmhmm and okay further discredits the notion, long held, that conversation is too "messy" to investigate, and that naturally-occurring speech is entirely idiosyncratic and the product of an individual's own preferences and individuality. That there is a systematic deployment of something as seemingly trivial as the use of okay and $\mathrm{mmhmm}$ comes as further evidence of Sacks' notion that "it is perfectly possible...to suppose...that wherever one happens to attack the phenomenon one is going to find detailed order. That is, one may alternatively take it that there is order at all points" (in Jefferson 1984a: 197).

\section{References}

Atkinson, M. (1992) Displaying neutrality: Formal aspects of informal court proceedings. In P. Drew and J. Heritage (Eds.), Talk at work. Cambridge: Cambridge University Press.

Beach, W. (1993) Transitional regularities for 'casual' "Okay" usages. Journal of Pragmatics analysis. J.M. Atkinson \& J. Heritage (Eds.), Cambridge: Cambridge University Press.

Clayman, S. (1993) Reformulating the question: A device for answering/not answering questions in news interviews and press conferences. Text 13.2: 159-188.

Dittman, A. \& L. Llewellyn (1967) The phonemic clause as a unit of speech decoding. Journal of Personality and Social Psychology 6: 341-349.

Drew, P. \& J. Heritage (Eds.) (1992) Talk at work. Cambridge: Cambridge University Press.

Ford, C., B. Fox, and S. Thompson (1966) Practices in the construction of turns: The "TCU" revisited. Pragmatics 6.3: 427-454.

Ford, C. \& S. Thompson (1996) Interactional units in conversation: Syntactic, intonational, and pragmatic resources for the management of turns. In E. Ochs, E. Schegloff \& S. Thompson (Eds.), Interaction and grammar. Cambridge: Cambridge University Press. 
Fries, C. (1952) The structure of English. New York: Harcourt, Brace.

Gill, V. (1994) How patients explain, how doctors respond: Lay explanations in medical interaction. Paper presented at the American Sociological Association Meetings, Los Angeles, CA.

Greatbatch, D. (1986) Aspects of topical organization in news interviews: The use of agenda-switching procedures by interviewers. Media, Culture, and Society 8: 441-455.

Halkowski, T. (1994) Realizing the illness: How patients present the discovery of their symptoms in the medical interview. Paper presented at the American Sociological Association Meetings, Los Angeles, CA.

He, W. (1993) Reconstructing institutions through talk: A discourse study of academic counseling encounters. Unpublished doctoral dissertation, Department of TESL/ Applied Linguistics, University of California, Los Angeles.

Heritage, J. (1984) A change of state token and aspects of its sequential placement. In J.M. Atkinson \& J. Heritage (Eds.), Structures of social action: Studies in conversation analysis. Cambridge: Cambridge University Press.

Heritage, J. (1985) Analyzing news interviews: Aspects of the production of talk for an overhearing audience. In T. Dijk (Ed.), Handbook of discourse analysis V3. New York: Academic Press.

Heritage, J. \& D. Greatbatch (1989) On the institutional character of institutional talk: The case of news interviews. In P.A. Forstorp (Ed.), Discourse in professional and everyday culture. Linköping: University of Linköping.

Heritage, J. \& S. Sefi (1992) Dilemmas of advice: Aspects of the delivery and reception of advice in interactions between health visitors and first-time mothers. In P. Drew \& J. Heritage (Eds.), Talk at work. Cambridge: Cambridge University Press.

Jefferson, G. (1978) Sequential aspects of storytelling in conversation. In J. Schenkein (Ed.), Studies in the organization of organisational interaction. New York: Academic Press.

Jefferson, G. (1994a) Notes on a systematic deployment of the acknowledgement tokens "Yeah" and "Mmhmm". Papers in Linguistics 17: 197-216.

Jefferson, G. (1984b) Transcript notation. In Structures of social action. Studies in conversation analysis. J.M. Atkinson \& J. Heritage (Eds.), Cambridge: Cambridge University Press.

Lerner, G. (1996) On the semi-permeable character of grammatical units in conversation: Conditional entry into the turn space of another speaker. In E. Ochs, E. Schegloff, \& S. Thompson (Eds.), Interaction and grammar. Cambridge University Press.

Merritt, M. (1984) On the use of 'okay' in service encounters. In J. Baugh \& J. Sherzer (Eds.), Language in use. Englewood Cliffs, NJ: Prentice-Hall.

Sacks, H., E. Schegloff, \& G. Jefferson (1974) A simplest systematics for the organization of turn-taking for conversation. Language, 50: 696-735.

Schegloff, E. (1982). Discourse as an interactional achievement: Some uses of 'uh huh' and other things that come between sentences. In D. Tannen (Ed.), Georgetown University Roundtable on Languages and Linguistics. Washington, DC: Georgetown University Press.

Schegloff, E. (1995) Sequence organization. MS in progress. 
Schegloff, E. \& H. Sacks (1973) Opening up closings. Semiotica 8: 289-327.

Whalen, M. \& D. Zimmerman (1987) Sequential and institutional contexts in calls for help. Social Psychology Quarterly 50.2: 172-185.

Yngve, V. (1970) On getting a word in edgewise. In Papers from the Sixth Regional Meeting, Chicago Linguistic Society. Chicago: Chicago Linguistic Society.

Zimmerman, D. (1984). Talk and its occasion: The case of calling the police. In D. Schiffrin (Ed.), Meaning, form, and use in context: Linguistic applications. Georgetown University Roundtable on Language and Linguistics. Washington, DC: Georgetown University Press. 